\title{
A QUEM INTERESSA A PROFISSIONALIZAÇÃO DOCENTE?
}

\author{
Bruna Senna Dias \\ Universidade Federal do Rio de Janeiro - UFRJ, Brasil \\ Carmen Teresa Gabriel \\ Universidade Federal do Rio de Janeiro - UFRJ, Brasil
}

\begin{abstract}
Resumo
Esse artigo tem por objetivo abordar questões referentes a profissionalização docente, levando em consideração a percepção de que, nos últimos tempos, a docência tem sido significada hegemonicamente como profissão, seja na produção acadêmica, seja na política educacional ou nos cursos de licenciatura. Em diálogo com as contribuições teóricas da abordagem discursiva pósfundacional, interessa-nos neste texto problematizar a temática da profissionalização docente questionando seus desdobramentos no processo de significação da docência nas políticas curriculares nacionais mais recentes, voltando nosso olhar especificamente para a Resolução CNE/CP n ${ }^{\circ}$ 2, de 20 de dezembro de 2019, que institui a BNC-Formação. A discussão se constrói no sentido de simultaneamente dar visibilidade as ambivalências que permeiam o processo de significação do termo "profissionalização" e fazer apostas em fechamentos provisórios que possibilitem o investimento em ouros sentidos possíveis.
\end{abstract}

Palavras-chave: Profissionalização da docência, Formação de professores, Política curricular.

\begin{abstract}
This article discusses issues related to teacher's professionalization, considering the perception that, in recent times, teaching has been hegemonically signified as a profession, whether in academic production, in educational policy or teacher training courses. In dialogue with post-foundational theory of discourse, we are interested in this article to problematize the teacher's professionalization and the consequences of this hegemonic discourse in the process of significance of teaching in the most recent national curriculum policies in Brazil for teacher training, the National Common Base for Teacher Training (BNC-Formação). The discussion aims to simultaneously give visibility to the ambivalences that permeate the discourse of teacher's professionalization and place bet in others possible meanings as temporary closure.
\end{abstract}

Keywords: Teacher's professionalization; Teacher training; Curriculum Policies. 
A gente quer ter voz ativa

No nosso destino mandar

Mas eis que chega a roda-viva

E carrega o destino pra lá

(Chico Buarque)

A história da profissão docente pode ser interpretada por meio da metáfora da Roda Viva, de que fala Chico Buarque na epígrafe que escolhemos para abrir esse texto. Em meio a defesa da autonomia profissional docente, buscando garantir sua voz ativa, os professores parecem estar constantemente lutando contra as tentativas de subalternização e regulação do seu trabalho, que parecem carregar o destino pra lá.

Com efeito, as interpretações sobre a prática profissional do trabalho docente produzidas a partir de uma perspectiva histórica, tendem a apontar que, a despeito das singularidades dos contextos históricos nos quais a ideia de profissionalização docente emerge e se consolida, a tensão entre autonomia e regulação é mobilizada de forma recorrente. Nóvoa (1995), por exemplo, argumenta, ao analisar a história da profissão docente em Portugal, que a profissionalização da docência é um processo alavancado pela estatização do ensino no século XVIII, marcado pela perda de controle da igreja sobre a escolarização e a vinculação dos professores como parte do quadro dos funcionários do Estado destacando que esse processo teve papel importante na organização dos professores como corpo profissional e "deve ser encarada como uma vontade partilhada do Estado e do corpo docente" (Nóvoa, 1995, p. 17). Roldão (2017), por sua vez, sublinha o caráter controvertido da questão da funcionarização dos professores, alertando para o risco de desvalorização do conhecimento profissional docente que ela acarreta.

Hypolito (2004), a partir da análise do contexto brasileiro, reconhece que esse processo de funcionarização pode ser compreendido a partir de duas dimensões distintas. Por um lado, o Estado assimila parte importante das demandas dos professores por profissionalização, como regulação dos processos de entrada na profissão, organização das carreiras docentes e dos cursos de formação de professores. Por outro lado, esse mesmo Estado assume o papel de regulador da profissão docente ao centralizar sob seu controle a organização dos sistemas escolares, o currículo e seus conteúdos e, consequentemente, o trabalho docente. $\mathrm{O}$ autor destaca que a funcionarização da docência expressa, portanto, o aspecto dicotômico da profissionalização dos professores que, ao mesmo tempo que se desvinculam da subordinação às comunidades religiosas, passam a se submeter ao controle do Estado.

O enfrentamento das questões sobre a profissionalização docente tem mobilizado nossos esforços na pesquisa educacional nos últimos tempos, sobretudo pela percepção de que hegemonicamente à docência tem sido significada como profissão, seja na produção acadêmica, seja na política educacional ou nos cursos de licenciatura ${ }^{1}$.

No caso dos textos acadêmicos, podemos observar, um renovado interesse nessa questão a partir do final do século XX, quando reformas educacionais nos Estados Unidos da América (EUA) e na Europa se valeram da retórica da profissionalização dos professores como forma de solucionar os problemas encontrados no ensino escolar. Desde então, tanto partidários da 
profissionalização, seja como estratégia de qualificação da formação e da prática docente, seja como discurso de afirmação da autonomia dos/as/es professores/as, quanto aqueles que a entendem como proletarização do trabalho docente, têm produzido inúmeros trabalhos que expressam a disputa em torno desse significante (Coelho; Diniz-Pereira, 2017; Evangelista, 2009; Tardif, 2013).

Não precisamos ir muito longe para encontrarmos na política educacional brasileira, sobretudo nas políticas curriculares voltadas para a formação de professores, exemplos de como o discurso da docência como profissão aparece de forma bastante destacada. A Resolução CNE/CP no 2, de 20 de dezembro de 2019, que institui a Base Nacional Comum para a Formação Inicial de Professores da Educação Básica (BNC-Formação), estabelece três dimensões fundamentais para a formação inicial de professores: conhecimento profissional, prática profissional e engajamento profissional. Ao longo da resolução o significante profissional é utilizado diversas vezes como forma de garantir a qualidade da formação docente proposta pelo documento.

Quanto aos cursos de formação de professores iniciativas na direção de uma formação que articule de forma intencional a escola e universidade, reconhecendo que ambas as instituições compartilham da corresponsabilidade de formar novos professores, têm sido traduzidas com uma proposta de formação profissional docente. Trata-se da busca por um entrelaçamento entre a formação e a profissão que vá além das relações mais tradicionais entre universidade e escola, reconhecendo a docência como uma profissão que se relaciona com o conhecimento de uma forma específica e que difere da forma como um especialista em ciências da educação ou em uma determinada disciplina se relaciona com o conhecimento (Gabriel, 2019; Gabriel; Leher, 2019; Nóvoa, 2017b).

O consenso em torno do caráter profissional da docência, no entanto, se limita à mobilização do significante "profissão", e seus derivados, que, no senso comum, traz sentido positivo de trabalho especializado, socialmente reconhecido (Dubar, 2012). Com efeito, a análise das lutas pelo processo de significação desse termo tende a mostrar como o uso do significante profissão se faz de forma bastante heterogênea e, por vezes, contraditórias. Assim, é possível que, usando os mesmos termos profissão, profissional, encontremos discursos sobre a docência que ora a defendem como prática profissional autônoma, com função específica e conhecimento próprio, ora visam instrumentalizá-la e regulá-la por meio de um entendimento de profissão que se traduz como atividade técnica, mecânica, repetitiva e controlada por outros que não os próprios docentes. É preciso levar em conta, portanto, que a intensificação do uso do termo profissional, menos do que expressar consensos políticos por meio da produção de sentidos homogêneos sobre a docência, traduz o acirramento de um campo de disputas sobre o entendimento desse significante. Caberia, portanto, interrogarnos: A quem interessa a profissionalização docente? Que linhas de força disputam a hegemonização de qual sentido particular desse termo? Entre valorização, subalternização ou regulação, em quais sentidos de profissionalização docente interessa-nos investir?

Em diálogo com as contribuições teóricas da abordagem discursiva pós-fundacional (Laclau, 2011, 2018; Laclau; Mouffe, 2015; Retamozo, 2009), interessa-nos neste texto problematizar a temática da profissionalização docente questionando seus desdobramentos 
no processo de significação da docência nas políticas curriculares nacionais mais recentes, voltando nosso olhar especificamente para a Resolução CNE/CP n $^{\circ} 2$, de 20 de dezembro de 2019, que institui a BNC-Formação. Assumir essa postura epistêmica tem sido a forma escolhida, em nosso grupo de pesquisa, para a produção de leituras políticas sobre as tensões e desafios que se colocam hoje para o campo educacional envolvendo reformas curriculares que afetam a produção tanto de currículos democráticos para a educação básica quanto dos currículos de licenciatura nas universidades públicas nos quais é possível perceber os efeitos das políticas de formação inicial e continuada de professores. Essa escolha teóricaepistemológica significa para nós, pesquisadores, realizarmos movimentos de deslocamento de um quadro de inteligibilidade no qual fomos formados e forjamos as lentes com as quais lemos e atuamos politicamente no mundo para um outro lugar epistêmico. Lugar esse que autoriza renunciarmos à ideia de fundamentos absolutos e metafísicos para a compreensão do social e que reconhece, sem negar a materialidade do mundo, a potência analítica de operamos com a ideia de que toda configuração social é significativa e produzida discursivamente em meio às lutas pela sua significação. Um lugar que exige enfrentarmos o desafio teórico-metodológico sintetizado no questionamento formulado por Hernandez (2014):

Como transitar de sistemas de pensamentos baseados em fundamentos necessários que explicam a origem do homem, da ciência ou do conhecimento para outras formas de compreensão que sustentam a ausência de fundamentos últimos? (Hernandez, 2014, p. 1198 - tradução livre).

Longe de pretendermos esgotar as possíveis respostas às questões anteriormente formuladas, nosso propósito aqui é dar visibilidade as ambivalências que permeiam o processo de significação do termo "profissionalização". Entendemos a presença dessas ambivalências como elemento produtivo e incontornável às lutas pela significação. Trata-se, pois, menos de superá-las ou eliminá-las na esperança de encontramos um sentido único, límpido, coeso e "mais verdadeiro", do que compreender os grupos de interesses em jogo que participam dessas disputas. Para tal, organizamos nossos argumentos, neste texto, em três seções. Na primeira seção discutimos a temática da profissionalização docente com destaque para os debates produzidos a partir do final do século XX que, se valendo da retórica da profissionalização (Bourdoncle, 2000), contribuíram para a produção de um discurso sobre a docência que coloca os professores na condição de sujeitos incompletos que precisam se profissionalizar para que possam compartilhar do mesmo estatuto das profissões socialmente reconhecidas e valorizadas. Na segunda parte, alisamos a forma como a BNCFormação mobiliza o significante profissional a partir de uma perspectiva particular de docência e de profissão. Na terceira e última parte tecemos nossos arremates parciais propondo nossas apostas para o enfrentamento da questão da profissionalização docente. 


\section{Profissionalizar os docentes: sentidos de docência em disputa}

A ênfase na profissionalização como alternativa de transformação da formação e da prática docente ganhou destaque no campo educacional a partir da década de 1980 em razão das reformas educacionais internacionais voltadas para a melhoria dos resultados dos alunos (Evangelista, 2009; Gauthier et al., 2013; Maués, 2003; Shulman, 2014; Tardif, 2013). Tardif (2013) afirma que desde essa época o movimento de profissionalização da docência "domina o discurso reformista internacional sobre o ensino e a formação dos professores do ensino básico obrigatório" (p. 552).

A palavra profissionalização funcionou como um slogan positivo que atendia as demandas de vários segmentos sociais (Hypolito, 2004; Shiroma; Evangelista, 2011). Se por um lado os professores e suas associações viam nesse termo uma valorização positiva do seu trabalho, que se equiparava às profissões mais bem estabelecidas, por outro, as propostas de reformas educacionais emanadas dos organismos multinacionais investiam em formas de racionalizar e padronizar a formação de professores em diferentes lugares do mundo sob a égide da "formação profissional".

Bourdoncle (2000) analisa a palavra "profissionalização" como sendo duplamente valorizada. A raiz da palavra - profissão - traz conotações majoritariamente positivas, como por exemplo a ideia de uma ocupação determinada de onde se pode tirar os meios de existência, o que em períodos de desemprego pode ser fortemente valorizado. O autor destaca que se por um lado a profissão compartilha com o ofício (métier) um valor positivo, pelo fato de ambos serem ocupações de onde se pode tirar os meios de existência, por outro lado a ideia de profissão é revestida de uma valorização distinta do ofício, uma vez que é compreendida como uma ocupação que tem um certo prestígio. Essa dupla valorização da raiz da palavra profissionalização - profissão - é acrescida pelo seu sufixo que designa um processo que conduz a uma condição melhor. Dessa forma, o significante profissionalização assume contornos de "palavra que designa um processo que conduz a um estado considerado melhor [e] tem chance de ser ela mesma empregada de maneira positiva, o que favorece o seu uso" (Bourdoncle, 2000, p. 117-118 - tradução livre).

O reconhecimento de que a palavra profissionalização traz consigo uma ideia de algo positivo nos ajuda a entender, em parte, o destacado interesse que tem sido dado à profissionalização da docência nas últimas décadas. Contudo, como nos provoca a pensar Tardif (2013), é preciso que em nossas análises sobre a profissionalização docente levemos em conta quais sentidos de profissão e profissionalização têm sido privilegiados nas reformas educacionais voltadas para a formação de professores.

É importante lembrar que a profissionalização da docência origina-se de um ideal tipicamente americano, uma espécie de mito estadunidense que se exporta para todo o planeta há trinta anos. Na América Latina e no Brasil, não deveríamos começar a desconfiar desse mito e a criticá-lo? (Tardif, 2013, p. 569). 
O questionamento a respeito da vinculação dos professores como profissionais não é discussão recente. Autores do campo educacional têm se debruçado nessa temática apontando para as armadilhas e possíveis riscos que se escondem por trás do slogan da profissionalização (Shiroma, 2003). A análise dos trabalhos que se dedicam a pensar a questão do estatuto profissional da docência revela que é possível delinearmos dois movimentos distintos no que se refere ao questionamento dos problemas e das vantagens de significar a docência como profissão.

O primeiro movimento que desatacamos diz respeito às críticas a corrente estruturalfuncionalista de interpretação das profissões. Esta abordagem, também denominada taxonômica, é a corrente dentro da sociologia das profissões norte-americana que inaugura as teorizações sobre as profissões. Em nome de uma suposta objetividade asséptica essa corrente postula que é por meio de critérios fixos e pré-definidos que se pode definir quais atividades são ou não são consideradas como profissão. Como nos lembra Costa (1995), estes critérios elencados para avaliar o grau de profissionalismo das atividades estão fortemente vinculados às profissões mais tradicionais, como medicina e direito, quase que feitos sob medida para excluir outras ocupações do seleto grupo das profissões e relegá-las ao estatuto menos prestigiado das semiprofissões.

Ludke (2002), em texto original de 1983, já questionava se assumir a docência como profissão levando em conta o paradigma da medicina não era reforçar justamente o lugar da docência como atividade não profissional, ou seja, que não se encaixa nos parâmetros estabelecidos. Nesse sentido, a pergunta sobre os professores serem ou não profissionais suscitaria o questionamento sobre quais as vantagens de aplicar aos professores os mesmos critérios que designam os médicos ou os juristas como profissionais. Em que medida essa comparação reforça ou subalterniza ainda mais a docência e os professores?

O segundo movimento que identificamos diz respeito às análises que vinculam a profissionalização da docência nas últimas décadas a uma tendência dos organismos multilaterais atrelada às novas demandas do mundo globalizado (Ball et al., 2013; Hypolito, 2004; Maués, 2003; Shiroma; Evangelista, 2011). Ball et al. (2013) articulam as reformas educacionais dos últimos trinta anos a uma agenda econômica global que tem servido de parâmetro para as formulações de políticas educacionais tanto no Brasil quanto em outros países como EUA, Inglaterra, Chile. Levando em conta a nova ordem mundial globalizada, as novas formas de acumulação capitalista, a introdução de novas tecnologias e o esgotamento do fordismo, um novo perfil de trabalhador "mais flexível, eficiente e polivalente" (Maués, 2003, p. 91) passou a ser exigido.

Nesse contexto, uma série de críticas foram direcionadas aos professores e à escola questionando sua capacidade de formar o trabalhador exigido pelo mercado. Tanto a formação de professores quanto os sistemas de educação passaram a ser encarados como instâncias que careciam de reformas "visando qualificar melhor as pessoas para enfrentarem um mundo mais competitivo, mais afinado com o mercado" (Maués, 2003, p. 91). Diante das transformações políticas, sociais e econômicas a educação despontava como ferramenta importante de alinhamento da nova ordem mundial. 
A profissionalização se consolida como tendência para a formação de professores quando "as autoridades políticas e educacionais lançam oficialmente nos Estados Unidos o projeto de profissionalização do ensino" (Tardif, 2013, p. 559) com o objetivo de melhorar o desempenho do sistema educativo, fazer a docência passar de ofício para profissão e construir uma base de conhecimento para o ensino. O contexto que marca essas reformas é a publicação de sucessivos relatórios na década de 1980 que denunciavam falhas no sistema escolar americano $^{2}$.

O objetivo de profissionalizar os professores para melhorar o ensino aparece de forma evidente. Uma das formas de garantir essa profissionalização era por meio do desenvolvimento de uma base de conhecimentos específicos para o ensino, como expresso no trecho a seguir: "O ensino não podia se profissionalizar e, a partir daí, melhorar o desempenho dos alunos, sem estar fundamentado em saberes especializados como em outras profissões" (Gauthier et al., 2013, p. 60). Dentro desse contexto despontaram pesquisas que procuravam definir qual era a base de conhecimento para o ensino como as de Gauthier et al. (2013), Shulman (2014) e Tardif (2014).

O discurso em favor de uma base de conhecimentos específicos da docência estava fortemente articulado a defesa da universitarização da formação de professores. Se os professores figuravam como profissionais, então era preciso estabelecer espaços e saberes específicos que organizassem sua formação. Shulman (2014), em texto publicado originalmente em 1987, destaca que "o ensino é, essencialmente, uma profissão que exige formação acadêmica. O professor é um membro da comunidade acadêmica” (p. 207). A elevação da formação dos professores ao nível superior foi justamente um dos eixos mais proeminentes das reformas educacionais nas décadas de 1980 e 1990, vinculando profissionalização à universitarização dos professores. A universidade seria a instituição garantidora de que os professores dominassem a base de conhecimentos específicos de sua profissão.

No entanto, a universitarização da formação de professores, apesar de colaborar para a elevação do prestígio social do magistério, contribuiu para desencadear "um processo de depreciação dos saberes produzidos pelos próprios professores, que deixam de ser reconhecidos (de fato) como produtores de saberes" (Sarti, 2012, p. 328). Os saberes e experiências dos professores em exercício, apesar de terem sido articulados na formação de novos professores, não alcançaram o mesmo espaço que os conhecimentos científicos nem a mesma legitimidade e prestígio social do que os saberes produzidos na universidade. A ênfase na profissionalização da docência mediante a universitarização resultou, portanto, no afastamento entre as instâncias formativas e de atuação profissional.

Pensando no lugar dado aos professores Nóvoa (1995) sinaliza que estes têm ocupado o lugar do morto, fazendo uma referência ao jogo de bridge, ou seja, "está presente, tem de ser levado em consideração, mas a sua voz não é essencial para fixar o desfecho dos acontecimentos" (p. 7). Sarti (2012) também recorre à essa mesma metáfora para refletir sobre as contradições que têm marcado o movimento de profissionalização do magistério e afirma que os professores da educação básica têm ocupado o lugar do morto tanto nas pesquisas em educação como na formação de professores. Eles figuram tanto como objetos 
de pesquisa como consumidores dessas mesmas pesquisas, mas nunca como protagonistas, nem na produção de conhecimento sobre sua própria profissão, nem na condução da formação de seus futuros colegas de profissão. Apesar da promessa de valorização, a ênfase na profissionalização da docência a partir da universitarização, não garantiu o fortalecimento dos saberes profissionais dos professores da educação básica, nem seu papel como formador de seus pares.

Diante das contradições que atravessam a constituição profissional da docência podemos nos perguntar em que medida a profissionalização empreendida ao longo das últimas décadas contribuiu para valorizar, subalternizar ou regular a docência. Hypolito (2004), para quem o processo de profissionalização é extremamente ambíguo e contraditório, argumenta que a profissionalização da docência é simultaneamente uma terra prometida e um sonho negado. É bom lembrar que a defesa da profissionalização dos professores a partir da década de 1980 tem como base a desconfiança no trabalho realizado pelos professores. Como já argumentamos, foi a partir da justificativa de que o ensino não era adequado às novas exigências do mundo global que a profissionalização da docência veio à tona como uma espécie de tábua de salvação para a educação. Apesar do discurso de profissionalização abarcar as demandas dos professores e suas organizações por maior autonomia profissional, melhores condições de trabalho e uma identidade descolada da ideia de docência como missão e sacerdócio religioso, ele também serviu de aglutinador das expectativas da economia global neoliberal para a educação. Assim, a busca pela profissionalização, ora se confunde com as lutas dos professores por autonomia pedagógica ora é pensada como estratégia de controle do trabalho docente (Hypolito, 2004).

Nesta seção procuramos apontar como a ideia de profissionalização docente tem sido objeto de deslocamentos conceituais em função dos discursos que a mobilizam. Entendemos que entrar na discussão teórico-epistemológica a respeito da profissionalização da docência é inscrever-se em um debate já há muito conhecido no campo educacional e tecido por variados e numerosos fios. Nosso interesse foi o de explorar alguns fios já tecidos em meio às lutas pela sua significação. Nosso objetivo, portanto, não foi o de produzir uma narrativa linear da construção dessa categoria, mas situar sua emergência e consolidação em um sistema de significação de forma a compreender sua vitalidade ao longo de mais de três décadas nos discursos a respeito da formação docente. $O$ desafio da próxima seção é o de revisitar a categoria profissionalização da docência à luz da teoria pós-fundacional analisando como a relação entre valorização, subalternização e regulação da profissão docente aparece BNC-formação de 2019.

\section{BNC-Formação: Que articulações discursivas para fixar quais sentidos de profissionalização?}

A escolha desse texto de lei como objeto de análise se justifica menos pela sua atualidade ou pelas resistências e críticas pertinentes que ele suscita do que pelo fato de ele se constituir como uma superfície textual que pode servir de ilustração para dar visibilidade ao jogo 
político em torno do uso do significante profissional na tentativa de fixação hegemônica de um sentido particular de docência. $\mathrm{O}$ adjetivo profissional é utilizado para qualificar os substantivos "conhecimento", "prática" e "engajamento", considerados como "as três dimensões fundamentais (...) que se integram e se complementam na ação docente" (Brasil, 2019, art. $4^{\circ}$ ).

Nessa perspectiva, importa, não perder de vista a contextualização em termos de conjuntura política que intervém nas condições de produção desse texto de lei. Publicada em 2019, sem debate público consistente, gerando muita polêmica e discursos contrários por parte das diferentes entidades do campo educacional, a BNC-Formação se inscreve em um conjunto de políticas curriculares recentes que traduzem o atual cenário político nacional de ameaça a projetos democráticos de sociedade.

Nesse contexto de enfraquecimento do espaço público, de recrudescimento e visões negacionistas, de intensificação da desigualdade social, de ampliação de movimentos e práticas discriminatórios, instituições como escola e universidade públicas são alvos de críticas que colocam em xeque o seu potencial formativo, produtivo e criativo. Não é por acaso que podemos ler no Parecer CNE/CP n ${ }^{\circ} 22 / 2019$, que fundamenta a Resolução que estabelece a BNC-Formação, a reatualização da tese da "urgência salvacionista", pautada na descrição de um cenário de precariedade generalizada da formação inicial docente, sem discriminação dos diferentes modelos formativos - público e privado; presencial e à distância existentes no contexto nacional - à qual se articula a oferta de uma solução "milagrosa", supostamente inovadora e forjada à margem da universidade pública (BRASIL, 2019b).

Os efeitos desse cenário no campo educacional têm sido objeto de denúncia das forças progressistas que vêm alertando sobre os avanços de grupos de interesses que sustentam a hegemonização de modelos de avaliação pautados em lógicas neoliberais, instrumentalistas, individualistas e mercadológicas (Ball et al., 2013; Shiroma, 2003; Shiroma; Evangelista, 2011) e que reforçam a "linguagem da aprendizagem" em detrimento da "linguagem da educação" (Biesta, 2013). Além de formularem ou defenderem reformas curriculares e a elaboração de políticas de formação de professores da Educação Básica compreendidas pelos pesquisadores e profissionais da área como um retrocesso (Dias, 2021).

Embora, em linhas gerais, tenhamos acordo com essas críticas, neste texto nos propomos a produzir uma análise que busque sublinhar tanto a filiação dessa resolução ao cenário político acima descrito quanto os vestígios de escape dessas tentativas de controle de uma fixação hegemônica de docência e formação docente igualmente presentes nessa superfície textual. Essa proposta de leitura nos parece potente para que possamos ir para além da linguagem da denúncia - certamente incontornável - e operar com a linguagem de possibilidades. Isso não significa investir em discursos ingênuos de otimismo pedagógico, mas sim, reconhecer a força analítica da ambivalência no terreno do político.

Focalizar nas estratégias discursivas mobilizadas nas disputas pela hegemonização de um sentido particular da interface docência -profissionalização, tais como desenvolvidas na BNC-formação, implica, no quadro de inteligibilidade aqui privilegiado, explorar tanto as tentativas de estabilização quanto os sinais de subversão a essas tentativas. Explorar a ambivalência dos sentidos de significantes disputados, como é o caso, neste texto, do termo 
"profissionalização", é um caminho metodológico que se filia à abordagem teórica pósfundacional. Assim, ao pretender fixar e estabilizar um sentido particular de profissionalização docente, a resolução em foco produz sentidos 'do que não é' essa profissionalização, mas que poderia ser, dependendo das relações assimétricas entre os grupos de interesse que participam do jogo político.

Reconhecer esses excessos de sentido, lembrar da contingência e provisoriedade de todo e qualquer processo de significação é uma forma de manter em aberto em nosso presente a possibilidade de novas enunciações. A reativação do político é pois, uma forma produtiva de resistir, de lutar contra políticas com as quais não compartilhamos os mesmos projetos de sociedade, os mesmos horizontes de expectativas que os nossos.

Optamos por proceder a análise da BNC-Formação a partir de três eixos de problematização que nos parecem fundamentais para a compreensão das diferentes estratégias mobilizadas nesse documento para afirmar um sentido de profissionalização docente: as disputas em torno do lócus da formação dos professores; a questão sobre o conhecimento profissional docente; a tensão entre responsabilização e autonomia dos professores. Nosso objetivo é mapear como o documento de 2019 mobiliza essas questões na construção de um sentido particular de profissão docente. Que articulações discursivas que contribuem para reforçar quais interesses? Para tal, consideramos esse texto de lei composto por nove capítulos, subdivididos em 30 artigos e inúmeros incisos, bem como o texto da BNC - Formação, anexada a essa Resolução como uma trama interdiscursiva atravessada por diferentes fluxos de significação que disputam sentidos, entre outros de profissionalização docente.

\section{Qual lócus privilegiado para formar qual profissional docente?}

Essa interrogação já é clássica nos debates educacionais acerca da formação inicial e continuada dos professores da educação básica (Sarti, 2013; 2019; Nóvoa, 2017a) Sua resposta, ainda que não consensual, tende a apontar, nessas últimas quatro décadas para uma convergência de interesses em torno do reconhecimento do papel incontornável da universidade no processo de formação desse profissional. Mais especificamente, a formação de professores no ensino superior tem sido encarada no campo acadêmico e nos debates políticos educacionais como a forma privilegiada de levar a cabo o projeto da profissionalização docente. Com efeito, a interface universitarização-profissionalização docente tem se constituído um objeto de reflexão que extrapola as fronteiras nacionais, podendo ser considerada como uma construção de um sistema de razão (Popkewits, 2012) no campo educacional para nomear a qualidade da formação docente e que tende a ir se tornando, em nosso presente, como o caminho natural e mais acertado.

Importa observar, no entanto, que essa tendência não aparece de forma inequívoca no texto de lei analisado. Já no primeiro artigo da Resolução fica claro que a universitarização é um caminho possível, mas não único, da formação inicial docente. Ao fazer referência aos propósitos dessa resolução, o artigo $1^{\circ}$ explicita que ela tanto "define as Diretrizes 
Curriculares Nacionais para a Formação Inicial em Nível Superior de Professores para a Educação Básica" quanto "institui a Base Nacional Comum para a Formação Inicial de Professores da Educação Básica (BNC-Formação)”. Ainda nesse mesmo artigo é possível ler que essa base "deve ser implementada em todas as modalidades dos cursos e programas destinados à formação de professores" (Brasil, 2019a, art. 1º, grifos nossos), deixando claro que os cursos de licenciatura em universidades públicas são um lócus possível, mas não exclusivo dessa formação.

A expressão "ensino superior" mobilizada na Resolução abre um amplo leque de possibilidades para pensar o lócus da formação profissional docente. A leitura atenta do documento permite afirmar que a universidade pública, como instituição formadora, aparece de forma esparsa e sem muita força. O próprio significante "universidade" não é mobilizado ao longo do documento. Apenas no inciso $\mathrm{V}$ do artigo $6^{\circ}$, percebe-se vestígios dessa instituição quando, entre os princípios relevantes para a política de formação de professores, inclui-se "a articulação entre a teoria e a prática para a formação docente, fundada nos conhecimentos científicos e didáticos, contemplando a indissociabilidade entre o ensino, a pesquisa e a extensão, visando à garantia do desenvolvimento dos estudantes" (Brasil, 2019a, art. 6, inciso $\mathrm{V}$, grifos nosso).

A não exclusividade da cultura universitária como lócus no processo formativo de professores da Educação Básica, em algumas situações particulares é ampliado para o ensino superior como um todo, como é possível ler nos dois artigos que se seguem:

Art. 17. Os cursos de Educação Superior e de Ensino Médio para a Formação de Professores Indígenas devem atender, também, e no que couber, às Diretrizes Curriculares Nacionais específicas instituídas pela Resolução CNE/CP no 1, de 7 de janeiro de 2015. (Brasil, 2019a)

Art. 18. Os cursos em Nível Médio, na modalidade Normal, destinados à formação de docentes da Educação Infantil e dos anos iniciais do Ensino Fundamental, além de cumprir as disposições desta Resolução, em especial as competências expressas na BNC-Formação, devem respeitar, no que não a contrariar, as Diretrizes Curriculares Nacionais específicas instituídas pelas Resoluções CNE/CEB no 2, de 19 de abril de 1999, e no 1, de 20 de agosto de 2003. (Brasil, 2019a)

Esse apagamento ou falta de precisão acerca da natureza da instituição do ensino superior que se quer privilegiar no documento contribui não apenas para manutenção dessa formação no nível do ensino médio, como também dificulta a consolidação do processo de universitarização em toda a sua complexidade. Essas estratégias discursivas abrem caminhos para a fragilização das formações oferecidas pelos cursos de licenciaturas, em particular das universidades públicas, reforçando os discursos desqualificadores dessa instituição como mencionado anteriormente.

Nessa mesma linha, os capítulos V e VI da Resolução, que versam sobre a formação em segunda licenciatura e a formação pedagógica, respectivamente, são outros indícios do 
enfraquecimento da aposta nos currículos de licenciatura como percursos complexos e integrados. As possibilidades de percurso tais como apresentadas nos artigos 19, 20 e 21 tendem a fragmentar o processo formativo e a fortalecer visões dicotômicas entre as dimensões pedagógica e disciplinar, inerentes à essa formação, reforçando assim uma universitarização incompleta (Sarti, 2012).

Outro aspecto que aponta para uma diminuição da importância da universidade (pública), nessa resolução refere-se à forma como a questão da formação continuada é abordada. No inciso VIII do artigo $6^{\circ}$, esse nível de formação é apresentado como componente essencial para a profissionalização docente e deve ser integrada ao cotidiano da escola considerando diferentes saberes e experiências docentes. A formação continuada em nível de pós-graduação não é sinalizada como um caminho esperado e desejado. Mais uma vez a estratégia de apagamento é mobilizada para estabilizar um sentido particular de docência que a afasta da cultura universitária como se essa fosse dispensável.

O que estamos querendo problematizar não são as múltiplas possibilidades de formação continuada que podem ser oferecidas, tampouco a valorização de ações formativas pensadas a partir das demandas da própria escola, mas o entendimento particular de universidade que se quer fixar. Não é difícil associar essas estratégias discursivas ao interesse de legitimar um sentido de universidade como espaço de formulação teórica descolada da realidade das escolas. Esse movimento, ao permitir formações aligeiradas na lógica da complementação, reatualiza velhos binarismos - teoria/prática; ciência/conteúdo escolar; conhecimento disciplinar/conhecimento pedagógico - que atravessam o campo educacional e que há muito têm sido questionados pelos estudiosos da área. A quem interessa reativar esse entendimento de universidade?

Esse questionamento é tão mais pertinente quando, paradoxalmente, é possível identificar, ao longo de diferentes momentos da Resolução, a defesa ou a intencionalidade da superação desses mesmos binarismos. Entre os fundamentos da formação dos professores e demais profissionais da Educação encontra-se de forma clara, no artigo $5^{\circ}$, "a associação entre as teorias e as práticas pedagógicas" (Brasil, 2019a, art.5\%, inciso II); ou ainda artigo $7^{\circ}$, que trata da organização curricular dos cursos superiores para a formação docente, onde é possível ler que um dos seus princípios norteadores é a "integração entre a teoria e a prática, tanto no que se refere aos conhecimentos pedagógicos e didáticos, quanto aos conhecimentos específicos da área do conhecimento ou do componente curricular a ser ministrado" (Brasil, 2019a, art. $7^{\circ}$, inciso VII).

O reconhecimento da importância da função social e política da universidade pública na formação dos professores da educação básica, não significa, todavia, sustentar uma argumentação inocente, ou uma crença que se fecha à qualquer possibilidade de contestação. Não se trata de defender qualquer universitarização. $O$ sentido desse significante também está em disputa. Entre a defesa de uma profissionalização docente no seio da cultura universitária a qualquer preço e a desvalorização desse lócus nesse processo, existe linhas argumentativas possíveis que vale a pena explorar. A própria ambivalência do texto da Resolução aponta essas possibilidades. 
No capítulo III - Da organização curricular dos cursos superiores para a formação docente - a articulação com a educação básica ao longo do processo de formação inicial é reafirmada e valorizada em vários momentos. O reconhecimento das "instituições da Educação Básica como parceiras imprescindíveis à formação de professores, em especial as das redes públicas de ensino" (Brasil, 2019, Art. 7º inciso IX) aparece em diferentes momentos no documento, deixando em aberto a possibilidade de articulações que permitem ampliar o lócus da formação para um entre lugar que se situa a meio caminho da escola e da universidade. De forma semelhante, no artigo $8^{\circ}$, entre os fundamentos pedagógicos que devem estar na base dos cursos destinados à Formação Inicial dos Professores para a Educação Básica, é possível ler: “o reconhecimento da escola da Educação Básica como lugar privilegiado da formação inicial do professor, de sua prática e sua pesquisa" (Brasil, 2019, art. $8^{\circ}$, inciso VII).

Esse entendimento do papel atribuído à escola vai ao encontro de estudos que tanto defendem a construção de um outro arranjo institucional - casa comum, terceiro-espaço envolvendo a definição do lugar institucional dessa formação (Nóvoa 2017a, Zeichner, 2010) quanto contribuem para fortalecer os discursos que investem na valorização desse profissional como sujeito produtor de conhecimentos específicos que participa diretamente na formação de seus futuros pares (Sarti, 2012; Senna Dias, 2018). No entanto, esse entendimento sobre o espaço da instituição escolar ao se articular, nesse documento, com sentidos de universidade, como mencionado anteriormente, produz efeitos contrários a essas leituras. Caberia aqui se perguntar: em que moldes é proposta a parceria entre escolas e redes de ensino com as instituições de formação de professores? Qual peso é dado a cada uma dessas instituições?

A defesa da articulação universidade-escola pública e a natureza dessa relação delineada nesse documento são movimentos ambivalentes e muitas vezes contraditórios. Como sustentar o argumento da defesa dessa articulação e, simultaneamente, negar a função política e epistemológica desses espaços, ao investir no discurso da centralidade da prática esvaziada da dimensão crítico-reflexiva?

A apropriação de críticas do próprio campo educacional deslocadas de seu contexto de formulação, sem o devido rigor metodológico e científico, mobilizadas para reafirmar interesses contrários aos defendidos pelos pesquisadores e professores pode ser compreendido igualmente como outra estratégia discursiva acionada nesse documento. Os desdobramentos dessa apropriação, se manifestam, por exemplo, na ênfase, em um praticismo - problematizado e desestabilizado nos debates da área, como se pode ler inclusive em pareceres do próprio Conselho Nacional de Educação (CNE) produzidos antes da BNCformação - como forma de lidar com a tensão teoria e prática ou ainda na indução ao deslocamento do lócus de formação docente da universidade pública para outras instituições formadoras, ao invés de defender o seu pertencimento como curso de identidade própria no seio do espaço acadêmico.

Nessa perspectiva, como veremos adiante, a formação docente tende a ser reduzida à transmissão de saberes e à mera execução de técnicas de ensino, passando a escola a ser vista apenas como um campo de aplicação de conhecimento produzidos em outros espaços. 


\section{Com quais conhecimento se forma um profissional docente?}

Basta uma breve leitura da Resolução de 2019 para nos darmos conta da centralidade atribuída à Base Nacional Comum Curricular (BNCC) que desde sua polêmica homologação em 2017 tem sido objeto de críticas e denúncias por parte de um número significativo de pesquisadores e profissionais da área. Essa observação inicial é importante, na medida em que esse atrelamento de propostas curriculares voltadas para públicos diferenciados interfere diretamente na definição do objeto de ensino-aprendizagem nos currículos de licenciatura bem como na natureza da relação que esses futuros professores estabelecem com esses conhecimentos curricularizados, específicos à sua profissão.

A leitura do parágrafo único do artigo $1^{\circ}$ não deixa dúvidas sobre a fusão entre as políticas curriculares voltadas para a educação básica e as políticas curriculares voltadas para formação de professores. Ainda que tenhamos em nossos estudos mais recentes (Gabriel, 2019) operado com o entendimento de currículos de licenciaturas como currículos híbridos envolvendo e articulando as demandas tanto da cultura escolar quanto da cultura universitária, isso não significa a defesa da articulação-fusão entre esses dois contextos formativos.

Interessante observar que uma das estratégias mobilizadas para sustentar essa fusão está diretamente relacionada ao entendimento da natureza da "relação estabelecida com o saber/conhecimento", bem como do próprio termo que nomeia o objeto de ensinoaprendizagem, matéria prima da ação docente. No que diz respeito ao sentido fixado para nomear aquilo que é legitimado e validado para ser ensinado e aprendido, chama a atenção a mobilização do significante 'competências' que passa assumir a função discursiva de ponto nodal nos processos de significação dos currículos de licenciatura e da educação básica. Como é possível verificar em diferentes momentos ao longo da Resolução, a principal referência da BNC-Formação é a BNCC da Educação Básica.

A BNC-formação se apresenta, assim, como documento condensador das competências profissionais dos professores de forma a garantir as "aprendizagens essenciais" dos estudantes da educação básica. A ideia de conhecimento escolar é reduzida e mesmo confundida com o próprio documento da BNCC. Com base nos mesmos princípios das competências gerais da BNCC são estabelecidas competências específicas para os docentes vinculadas a três dimensões fundamentais, já mencionadas anteriormente: conhecimento profissional, prática profissional e engajamento profissional.

A separação das dimensões de conhecimento e prática profissional reforçam o sentido aplicacionista da docência que perpassa todo o documento que trata conhecimento e prática como instâncias distintas. O professor profissional da BNC-Formação é aquele capaz de aplicar currículos pré-fabricados. Na dimensão do engajamento profissional o que ganha destaque é a perspectiva individualista e que desonera o Estado do lugar de garantir as condições para a formação profissional dos professores, como discutiremos a seguir. 


\section{Autonomia profissional: entre a desobrigação do Estado e a responsabilização dos professores}

Nas últimas décadas, os debates sobre a interface docência-profissionalização têm sido atravessados por uma nova concepção do papel do Estado na gestão dos serviços públicos, pela defesa de um mercado escolar pautado pela competitividade entre as instituições, por avaliações padronizadas e objetivos curriculares comparáveis, pela desregulamentação dos sistemas de ensino e uma maior autonomia das instituições escolares. É preciso ter cautela, entretanto, nas análises que vinculam o crescimento da autonomia das escolas a uma aposta na capacidade profissional de autogestão da escola e dos professores. Em muitos casos o que fica evidente é um descomprometimento do Estado com a educação pública por meio de uma política de responsabilização que, em nome de um suposto protagonismo docente, cobra resultados dos professores sem lhes dar as mínimas condições de realizarem seu trabalho.

Na BNC-Formação é possível percebermos que a significação da docência como profissão é feita em muitos momentos pelo reforço da responsabilidade individual dos licenciandos frente ao seu próprio desenvolvimento profissional. Dentre as três dimensões fundamentais da docência que organizam o documento a dimensão do engajamento profissional é a que mais dá o tom do protagonismo individual imposto aos professores.

Não se trata de negarmos a importância de cada profissional se envolver ativamente com sua formação, seja ela inicial ou continuada, mas sim de questionarmos qual a responsabilidade do Estado na oportunização de experiências formativas e de aprofundamento na cultura profissional docente. A chamada ao protagonismo docente e ao seu desenvolvimento profissional vem acompanhada de estratégias que liberem os professores da sala da aula, sem comprometimento dos seus vencimentos, para que possam investir em sua formação? Há incentivos salariais que estimulem os professores a buscarem por cursos de formação continuada e formas de aceleração na progressão da carreira que reconheçam e valorizem o investimento feito pelos professores em sua formação?

No artigo $6^{\circ}$, inciso I, lemos que a formação docente para todas as etapas e modalidades da educação básica é compromisso do Estado. No entanto, além dessa afirmação genérica nada mais é dito da responsabilidade do Estado com os professores. Estes, por sua vez, são repetidamente convocados a se responsabilizarem individualmente pela construção de sua vida profissional, como podemos ler no artigo $7^{\circ}$. Dentre os princípios norteadores da formação inicial de professores está o "fortalecimento da responsabilidade, do protagonismo e da autonomia dos licenciandos com o seu próprio desenvolvimento profissional" (Brasil, 2019a, art. $7^{\circ}$, inciso VI). A questão que se coloca é sobre o que os professores/licenciandos devem se responsabilizar? Como são chamados a exercerem sua autonomia e protagonismo?

O que a leitura da BNC-Formação nos permite argumentar é que não se trata de uma autonomia frente à tomada de decisões cotidianas que se impõe à profissão docente. Quanto ao trabalho dos professores o documento é bastante prescritivo, reduzindo o papel do professor a um mero aplicador de propostas curriculares pré-estabelecidas, privando-o do lugar de autoria no/do trabalho docente. Como já discutimos, a instância maior de 
organização da formação e da prática docente é a BNCC que deve ser apropriada pelos docentes/licenciandos e garantida aos estudantes da educação básica como condensadora das “aprendizagens essenciais". Ora, se os professores não participam da definição das escolhas curriculares nem da organização do seu trabalho em que medida devem exercer seu protagonismo e sua autonomia? Menos do que o reconhecimento da capacidade profissional dos professores como produtores de conhecimento a autonomia, na BNC-Formação, ganha contornos de desobrigação do Estado frente às condições de desenvolvimento profissional dos professores.

O discurso de profissionalização dentro de um contexto neoliberal, onde a lógica do mercado é o que regula as relações, tem contribuído para fixação de um sentido de profissão docente que está assentado "numa relação antagônica com o profissionalismo tradicional" (Ball et al., 2013, p. 17). Se os marcadores tradicionais de uma profissão eram, dentre outras, o domínio de um conhecimento específico e a autonomia para exercer um serviço especializado, as formas de profissionalismo docente alimentadas nas últimas décadas pelas reformas educacionais têm dado novos contornos a autonomia dos professores, que passa a ser submetida a exigências de performatividade (Ball et al. 2013).

A cultura da performatividade, de acordo com Ball et al. (2013), opera como um regime de responsabilização e prestação de contas dos professores. Os resultados de aprendizagem e a qualidade da educação são diretamente relacionados ao desempenho dos professores que, ao mesmo tempo que são culpabilizados individualmente, são constantemente comparados com seus colegas.

O crescimento de trabalhadores não docente assumindo as funções de salas de aula; legislações mais flexíveis para a contratação de professores; pagamento mediante desempenho, subordinação do trabalho docente ao controle do Estado, que define o que e o como ensinar, retirando dos professores seu julgamento profissional; ensino com ênfase nas habilidades e competências requisitadas pelo mercado de trabalho, entre outras questões, têm marcado a profissão docente dentro de uma cultura de performatividade. Assim, apesar do crescimento da retórica a favor da profissionalização o que se percebe é uma série de medidas que contribuem para subalternizar e regular a profissão docente, reduzindo o campo de possibilidades da autoria do trabalho dos professores ao articular sentidos de autonomia a escolhas obrigatórias pré-estabelecidas. Ao mesmo tempo que o texto menciona aspectos que remetem à importância e pertinência da valorização do professor, atribui aos docentes a tarefa individual de se responsabilizarem por seu desenvolvimento profissional, sem garantir, entretanto, condições objetivas de trabalho e salário que favoreçam esse desenvolvimento. O que pode vir a contribuir para reforçar o discurso da culpabilização dos professores pelos fracassos do sistema educacional escolar

Parece que de todos os lados o estatuto profissional da docência está comprometido. Ou os professores não se enquadram nos critérios definidores das profissões mais socialmente estabelecidas ou, quando chamados a se profissionalizarem, são desqualificados em sua autonomia profissional e submetidos a práticas e mecanismos de controle e regulação do seu trabalho, que os colocam, mais uma vez, no lugar da falta e da subalternização. A BNCFormação, enquanto superfície textual que expressa as ambivalências em torno da 
significação da docência como profissão, ao mesmo tempo que enfatiza a autonomia e protagonismo docente nega a importância da formação intelectual e política mais ampla do profissional da educação básica. Ao fortalecer um sentido de docência vinculado ao domínio técnico, a Resolução de 2019 reedita perspectivas instrumentalistas situando o professor numa posição subalternizada em meio a um sistema historicamente hierarquizado de saberes.

\section{Apostando em mais um lance no jogo da significação da profissão docente}

Diante das contradições que atravessam a constituição da docência como profissão aqui discutidas a pergunta que não quer se calar é: a quem interessa a profissionalização da docência? Afinal, se os sentidos hegemonizados de profissão docente não cumpriram a promessa de valorização social da docência, não garantiram o reconhecimento dos professores como produtores de conhecimento, nem lhes conferiu maior autonomia e participação nas decisões sobre a organização do seu trabalho nem na formação de novos docentes, como e por que continuar investindo na definição da docência como atividade profissional?

Dentro do quadro teórico pós-fundacional que temos operado em nossas pesquisas no campo educacional a disputa em torno da significação das coisas no mundo é uma operação discursiva que não cessa jamais. Discurso, entendido como "território primário da construção da objetividade enquanto tal" (Laclau, 2018, p. 116), ocupa um lugar instituinte na produção de toda ordem social (Laclau, Mouffe, 2015).

Entendemos, assim, que o processo de significação da docência se dá mediante a produção de diferentes discursos em disputa. Uma vez que nenhum conceito traz em si mesmo um sentido que lhe seja intrínseco, seu significado só ganha forma na medida em que diferentes elementos se relacionam fixando um sentido particular para tal objeto. A definição dos professores como profissionais, portanto, não se define por si mesma, mas a partir da relação diferencial com outros elementos.

Trata-se, pelo contrário, de reconhecer que os sentidos hegemonizados contingencialmente em cada tempo histórico são frutos de disputas em função das diferentes lutas e demandas políticas daquele tempo presente específico. O sentido de identidade docente está sendo disputado em diferentes arenas, como por exemplo na legislação, nas organizações da sociedade civil, em artigos acadêmicos, na mídia, nos currículos de licenciatura, nas provas de concurso para ingresso na carreira docente, entre outros. Todas essas instâncias, ao mesmo tempo que expressam as lutas hegemônicas em torno da definição de docência, participam elas mesmas dessas disputas, hegemonizando determinados sentidos em detrimento de outros.

No atual momento histórico em que vivemos o uso do significante profissão/profissional para qualificar a docência nos parece ainda um termo "bom para pensar" (Hall, 2014). O investimento em sentidos de docência como vocação/sacerdócio ou como trabalho que se aprende eminentemente pela prática em serviço, ficando a fundamentação teórica como 
aspecto menos importante ou até mesmo dispensável, nos parece ainda mais complicados se quisermos defender os professores como sujeitos que lidam, mobilizam a e produzem conhecimentos e que exercem uma função social específica e complexa que demanda formação em nível superior. Nossa aposta no investimento de outros sentidos possíveis para a significação da docência como profissão se sustenta na afirmação de que o significante profissão, como qualificador da docência, ocupa a função discursiva de "significante vazio" (Senna; Gabriel, 2021).

A fixação de um determinado sentido de identidade docente é uma operação hegemônica, onde um sentido particular assume a representação de uma totalidade incomensurável. Se não existem fundamentos dados a priori não podemos falar em identidades determinadas de uma vez por todas. Assumir, portanto, a identidade docente como profissão, ou sacerdócio, ou ocupação, é hegemonizar/universalizar sentidos particulares que estão dentro da incomensurabilidade do Social.

A universalidade específica que a operação hegemônica promove não tem conteúdo próprio e decorre da relação entre a lógica da equivalência e a lógica da diferença. A lógica da equivalência se caracteriza pela articulação de diferentes elementos que se aproximam, não porque são iguais, mas justamente por fazerem diluir suas diferenças em prol da hegemonização de um sentido particular. É a oposição a um inimigo comum que estabelece a unidade dos elementos que se aproximam pela cadeia de equivalência, e não uma suposta positividade a priori que esses elementos compartilhem. Assim, podemos entender que a definição dos professores a partir do significante profissional não parte de um sentido positivo sobre os professores. Antes, sua definição está atrelada a constituição de um sentido de docência ao qual se quer contrapor.

A lógica da diferença exerce a função de corte radical nesse processo de significação, produzindo uma relação antagônica que se constitui como exterior constitutivo dos sentidos aproximados por equivalência. Como colocado por Mouffe (2015) "toda ordem se baseia na exclusão de outras possibilidades" (p. 16). As lógicas da equivalência e da diferença nos colocam diante da questão entre o universal e o particular. Laclau (2011) argumenta que se o paradoxo universal-particular for, de uma vez por todas, resolvido então não há mais sentidos a serem disputados. Todo processo de significação só tem possibilidade de existência porque o universal não tem conteúdo específico e sua estruturação se sustenta em significantes vazios. O que parece um dilema, a ausência de sentido fundamental que ordene as coisas do mundo, pode ser politicamente interpretado como possibilidade perene de desestabilização dos sentidos hegemonicamente sedimentados e de investimento em outros sentidos que nos interessem disputar.

A categoria analítica significante vazio é fundamental no entendimento de processos de significação percebidos como simultaneamente impossíveis e necessários. Um sentido particular ao se hegemonizar, ou seja, ao assumir o lugar da universalidade, se esvazia de sua particularidade para que consiga abarcar, por equivalência, outros sentidos particulares em torno de si e, assim, fixar, ainda que parcialmente, um sentido específico. Uma vez que a totalidade/universalidade é um objeto impossível, a particularidade que se hegemoniza tende 
a tornar-se um significante vazio visto que "sua própria particularidade encarna uma completude inalcançável” (Laclau, 2018, p. 120).

Para Laclau (2011) a hegemonia só é possível em função da existência de significantes vazios. Ao se hegemonizar como sentido universal o sentido particular esvazia seu caráter diferencial para assumir-se como cadeia equivalencial de múltiplas demandas, e "como resultado de seu próprio êxito, a operação hegemônica tende a romper seus vínculos com a força que foi sua original promotora e beneficiária" (Laclau, 2011, p. 79).

Se concordarmos com Laclau (2018), quando o autor afirma que "a identidade hegemônica torna-se algo da ordem de um significante vazio" (p. 120 - grifo original), então, nos parece pertinente a afirmação de que a hegemonização do significante profissional, como marcador de uma determinada identidade de docência, pode ser lido como um significante vazio. Afinal,

Esvaziado de sentidos particulares, o significante profissional, fixado hegemonicamente como qualificador da docência, conforma diferentes processos de significação que tendem ora a atender às demandas iniciais de valorização dos professores, ora a reforçar práticas de subalternização da docência. (Senna, Gabriel, p. 49).

Assumir o significante profissional como significante vazio é assumir as possibilidades de investimento em outros sentidos de profissão e profissionalização docente. A aposta que temos feito é do investimento em um sentido de olhe a profissão docente por dentro, sem condicioná-la a listas pré-definidas que parecem feitas sob medida para condenar a docência a um lugar não profissional.

Três aspectos nos parecem incontornáveis na defesa que queremos investir. A formação profissional de professores deve estar assentada tanto na universidade quanto na escola, reconhecendo essas duas instâncias como espaços fundamentais de aprendizagem da profissão docente apostando na relação horizontal e não hierarquizada entre ambas. Não apenas esses espaços, mas os profissionais que atuam em cada um deles se configuram como agentes fundamentais da formação de novos professores. Consideramos, portanto, imprescindível à formação profissional dos novos professores a articulação intencional e sistemática entre a universidade e a escola, espaço privilegiado de exercício da profissão docente.

O segundo aspecto que julgamos fundamental é o reconhecimento dos professores como produtores de conhecimento. Reconhecer que professores não são aplicadores de currículos é afirmar sua capacidade de autonomamente tomar decisões sobre seu trabalho, a partir do julgamento profissional que fazem do contexto e das demandas que se impõem no seu cotidiano. Afinal como nos lembra Biesta (2013)

(...) os profissionais da educação têm um papel crucial a desempenhar no processo de definição das necessidades, porque uma parte importante de sua competência profissional reside nesse ponto, um papel que precisamente os distingue dos 
vendedores, cuja única tarefa é entregar as mercadorias ao cliente (Biesta, 2013, p.41).

Em terceiro lugar destacamos que a construção da profissão docente passa pelo fortalecimento das condições objetivas de construção de uma carreira no magistério e pela garantia de salários condizentes com uma profissão complexa e específica como a docência. Enquanto a docência figurar como bico, trabalho temporário ou emprego de espera, em que o professor está apenas aguardado outra colocação melhor no mercado de trabalho, nossos esforços em prol do fortalecimento do reconhecimento profissional da docência estarão comprometidos. Consideramos importante a aposta em sentidos de profissionalização docente que não dicotomize autonomia com funcionarização. Como já destacamos, algumas análises afirmam que o ingresso dos professores no quadro de funcionários do Estado foi aspecto fundamental no processo de profissionalização da docência. Resgatar esse aspecto da história da profissão docente talvez nos ajude a lançar outros olhares para a relação entre professores e poder público, não como relação que deslegitima a profissionalidade docente, mas como aspecto fortalecedor da docência como profissão. Sobretudo pela garantia de condições que favoreçam a formação continuada, a progressão na carreia e a participação dos professores nas decisões concernentes às redes e instituições de ensino.

A discussão que nos propomos a fazer, pensando sentidos de profissionalização à luz da BNC-Formação de 2019 e tendo como lente de análise a teoria do discurso pós-fundacional, foi a forma que encontramos para continuarmos produzindo outras leituras políticas do campo educacional e nos lançarmos também nas disputas em torno da hegemonização de um sentido possível para propalada profissionalização da docência. Como nos lembram Laclau e Mouffe (2015) "a impossibilidade de uma fixação última de sentido implica que deveria haver fixações parciais, do contrário, o fluxo das diferenças seria impossível. Mesmo para que se possa diferir, subverter o sentido, há de haver um sentido" (p. 187). Assim, as reflexões aqui produzidas além de questionar sentidos de profissionalização docente são um convite a que continuemos explorando esta ideia na pauta pós-fundacional de forma a politizar radicalmente os processos de significação da docência ao mesmo tempo que apostamos em fechamentos contingentes. Mesmo sem garantia e sabendo que a roda viva sempre joga o destino pra lá, insistimos em querer ter voz ativa e com nosso futuro sonhar.

\section{Notas:}

1. A produção deste texto está diretamente vinculada aos estudos que temos realizado dentro de dois projetos de pesquisa em curso: "Currículo como espaço biográfico: subjetivação e profissionalização docente em múltiplos tempos e espaços" (CNPq / Bolsa de produtividade Processo n. 312368/2018-6) e "Currículo como espaço biográfico: conhecimento, sujeitos e demandas em diferentes percursos formativos" (CNE/FAPERJ, processo n.E-26/202-931/2017).

2. Em 1983 o relatório A Nation At Risk: The Imperative For Educational Reform anunciava que as bases educacionais da sociedade americana caminhavam para a degradação. Em 1986 são publicados outros dois relatórios que, diante do cenário de desgaste do sistema escolar, propõem a reforma do sistema de ensino. 
O relatório Tomorrow's Teachers do grupo Holmes e o relatório A Nation Prepared: Teachers for de 21st Century, do Carnegie Task partilhavam o mesmo diagnóstico quanto a realidade educacional americana e as mesmas possibilidades de superação.

\section{Referências}

BALL, Stephen J. et al. A constituição da subjetividade docente no Brasil: um contexto global. Revista Educação em Questão, v. 46, n. 32, 2013, p. 9-36. Disponível em https://doi.org/10.21680/19811802.2013v46n32ID5114. Acesso em: 13 set. 2021.

BIESTA, Guert. Para além da aprendizagem: Educação democrática para um futuro humano. Belo Horizonte, Editora Autêntica, 2013.

BOURDONCLE, Raymond. Professionnalisation, formes et dispositif. Recherche et Formation, Paris, n. 35, 2000, p. 117-132. Disponível em: https://www.persee.fr/doc/refor_0988-1824_2000_num_35_1_1674. Acesso em 13 set. 2021.

BRASIL. Resolução CNE/CP nº 02/2019. Define as Diretrizes Curriculares Nacionais para a Formação Inicial de Professores para a Educação Básica e institui a Base Nacional Comum para a Formação Inicial de Professores da Educação Básica (BNC-Formação). Brasília, 2019a.

BRASIL. Parecer CNE/CP no 22/2019. Diretrizes Curriculares Nacionais para a Formação Inicial de Professores para a Educação Básica e Base Nacional Comum para a Formação Inicial de Professores da Educação Básica (BNC-Formação). Brasília, 2019b.

COELHO, Ana Maria Simões; DINIZ-PEREIRA, Júlio Emílio. Olhar o magistério no próprio espelho: O conceito de profissionalidade e as possibilidades de se repensar o sentido da profissão docente. Revista Portuguesa de Educação, v. 30, n. 1, 2017, p. 7-34. Disponível em: https://doi.org/10.21814/rpe.10724. Acesso em: 13 set. 2021.

COSTA, Marisa Cristina Vorraber. Trabalho docente e profissionalismo. Porto Alegre: Sulina, 1995.

DIAS, Rosanne Evangelista. BNCC no contexto de disputas: implicações para a docência. Revista Espaço do Currículo, v. 14, n. 1, 2021, p. 1-13. Disponível em: https://doi.org/10.22478/ufpb.19831579.2021v14n1.57075. Acesso em 13 set. de 2021.

DUBAR, Claude. A construção de si pela atividade de trabalho: a socialização profissional. Cadernos de Pesquisa [online]. v. 42, n. 146, 2012, p. 351-367. Disponível em: https://doi.org/10.1590/S010015742012000200003. Acesso em: 13 set. 2021.

EVANGELISTA, Olinda. Sentidos de profissionalização docente. In: SOUZA, Donaldo Bello de; MARTINEZ, Silvia Alícia (org.). Educação Comparada: rotas de além-mar. São Paulo: Xamã, 2009, p. 407-428.

GABRIEL, Carmen Teresa. Complexo de Formação de Professores: uma experiência (inter)institucional em curso. Profesorado - Revista de currículum y formación del profesorado, v. 23, p. 189-209, 2019.

GABRIEL, Carmen Teresa; LEHER, Roberto. "Complexo de Formação de Professores" da UFRJ: desafios e apostas na construção de uma política institucional. Formação em movimento, Rio de Janeiro, v.1, n.2, p. 219-237, jul./dez. 2019.

GAUTHIER, Clermont. et al. Por uma teoria da Pedagogia: pesquisas contemporâneas sobre o saber docente. $3^{\text {a }}$ ed. Ijuí: Editora INIJUI, 2013.

HALL, Stuart. Quem precisa da identidade? In: SILVA, Tomaz Tadeu; HALL, Stuart; e WOODWARD, Kathryn (org.). Identidade e diferença: a perspectiva dos estudos culturais. Petrópolis: Vozes, 2014, p. 103-133.

HERNANDEZ, Dulce Maria Carrera. El sujeto en la trama: biografía y poder en-clave posfundacional. Revista Mexicana de Investigation Educativa, Mexico, vol.19, n.63, out/dez, 2014, p.1195-1220. Disponível em: 
https://www.redalyc.org/pdf/140/14032016009.pdf. Acesso em 13 set. 2021.

HYPOLITO, A. M. Teachers' work and professionalization: the promised land or dream. Journal for Critical Education Policy Studies, v. 2, n. 2, set/2004, p. 203-226. Disponível em: http://www.jceps.com/wpcontent/uploads/PDFs/02-2-07.pdf. Acesso em: 13 set. 2021.

LACLAU, Ernesto. A razão populista. São Paulo: Três estrelas, 2018.

LACLAU, Ernesto. Emancipação e Diferença. Rio de Janeiro: EdUERJ, 2011.

LACLAU, Ernesto; MOUFFE, Chantal. Hegemonia e estratégia socialista: por uma política democrática radical. São Paulo: Intermeio; Brasília: CNPq, 2015.

LUDKE, Menga. O educador: Um profissional. In: CANDAU, Vera (org.). Rumo a uma nova didática. Petrópolis: Editora Vozes, 2002, p. 73-85.

MAUES, Olgaíses Cabral. Reformas internacionais da educação e formação de professores. Cadernos de Pesquisa. São Paulo, n. 118, mar. 2003. p. 89-118. Disponível em: https://doi.org/10.1590/S010015742003000100005. Acesso em: 13 set. 2021.

MONTEIRO, A. Reis. Profissão docente: profissionalidade e autorregulação. São Paulo: Cortez, 2015.

MOUFFE, Chantal. Sobre o Político. São Paulo: Editora WMF Martins Fontes, 2015.

NÓVOA, António. O passado e o presente dos professores. In: NÓVOA, A. (Org.). Profissão professor. $2^{\mathrm{a}}$ ed. Porto, Portugal: Porto Editora, 1995, p. 13-34.

NÓVOA, António. Firmar a posição como professor, afirmar a profissão docente. Cadernos de Pesquisa, São Paulo, v. 47, n. 166, p. 1106-1133, dez. 2017a. Disponível em: https://doi.org/10.1590/198053144843. Acesso em 13 set. 2021.

NÓVOA. António. Um novo modelo institucional para a formação de professores na Universidade Federal do Rio de Janeiro. Perspectivas em Educação Básica, Rio de Janeiro, v. 1, 2017b, p. 12-27. Disponível em: https://drive.google.com/file/d/11OntW3Nc7hgh-KIWX0qdYTaTb2bWKHIb/view. Acesso em: 13 set. 2021.

POPKEWITZ, Thomas. O duplo significado de cosmopolitismo e os estudos comparados de educação. In: COWEN, R.; KAZAMIAS, A.; ULTERHALTER, E. (org.). Educação comparada: panorama internacional e perspectivas; v. 1. Brasília: UNESCO, CAPES. 2012, p. 467-488.

RETAMOZO, Martin. Las demandas sociales y el estúdio de los movimientos sociales. Cinta Moebio, Santiago, v. 35, 2009, p. 110-127. Disponível em: https://scielo.conicyt.cl/pdf/cmoebio/n35/art03.pdf. Acesso em: 13 set. 2021.

ROLDÃO, Maria. do Céu. Conhecimento, Didáctica e Compromisso: o triângulo virtuoso de uma profissionalidade em risco. Cadernos de Pesquisa, v. 47, n.166, out/dez, 2017, p. 1134-1149. Disponível em: https://doi.org/10.1590/198053144367. Acesso em: 13 set. 2021.

SARTI, Flávia. O triângulo da formação docente: seus jogadores e configurações. Educação e Pesquisa. v. 38, n. 2, jun. 2012, p. 323-338. Disponível em: https://doi.org/10.1590/S1517-97022012000200004. Acesso em 13 set. 2021.

SARTI, Flavia Medeiros. Pelos caminhos da universitarização: reflexões a partir da masterização dos IUFM franceses. Educação em Revista [online]. v. 29, n. 4, 2013, p. 215-244. Disponível em: https://doi.org/10.1590/S0102-46982013000400010. Acesso em 13 set. 2021.

SARTI, Flavia Medeiros. O curso de pedagogia e a universitarização do magistério no Brasil: das disputas pela formação docente à sua desprofissionalização. Educação e Pesquisa [online]. v. 45, 2019, p. 1-18. Disponível em: https://doi.org/10.1590/S1678-4634201945190003. Acesso em 13 set. de 2021.

SENNA DIAS, Bruna. TORNAR-SE PROFESSOR: sentidos de docência negociados no currículo de Pedagogia da UFRJ. Rio de Janeiro, 2018. Dissertação (Mestrado em Educação) - Programa de PósGraduação em Educação / Faculdade de Educação, Universidade Federal do Rio de Janeiro, Rio de Janeiro, 
2018.

SENNA, Bruna; GABRIEL, Carmen Teresa. Formação profissional docente: um significante vazio em disputa. In: GABRIEL, Carmen Teresa; MARTINS, Marcus Leonardo Bomfim. Formação Docente e Currículo: conhecimentos, sujeitos e territórios. Rio de Janeiro: Mauad X, 2021, p. 43-60.

SHIROMA, Eneida Oto; EVANGELISTA Olinda. Avaliação e responsabilização pelos resultados: atualizações nas formas de gestão de professores. PERSPECTIVA, Florianópolis, v. 29, n. 1, jan./jun. 2011, p. 127-160. Disponível em: https://doi.org/10.5007/2175-795X.2011v29n1p127. Acesso em: 13 set. 2021.

SHULMAN, Lee S. Conhecimento e ensino: fundamentos para a nova reforma. Cadernos Cenpec. v. 4, n. 2 , São Paulo, dez. 2014, p.196-229. Disponível em; http://dx.doi.org/10.18676/cadernoscenpec.v4i2.293. Acesso em: 13 set. 2021.

TARDIF, Maurice. A profissionalização do ensino passados trinta anos: dois passos para a frente, três para trás. Educação \& Sociedade, Campinas, v. 34, n. 123, abr/jun, 2013, p. 551-571. Disponível em: https://doi.org/10.1590/S0101-73302013000200013. Acesso em: 13 set. 2021.

ZEICHNER, Kenneth. Repensando as conexões entre a formação na universidade e as experiências de campo na formação de professores em faculdades e universidades. Educação, Santa Maria: UFSM, v. 35, n. 3, set./dez. 2010, p. 479-504. Disponível em: https://doi.org/10.5902/198464442357. Acesso em: 13 set. 2021.

\section{Correspondência}

Bruna Senna Dias: É doutoranda e mestre em educação pelo Programa de Pós-Graduação em Educação da Universidade Federal do Rio de Janeiro (PPGE/UFRJ). Membro do Grupo de Estudos Currículo, Conhecimento e Ensino de História (Gecceh). Graduada em Pedagogia já atuou como professora das séries iniciais do ensino fundamental e atualmente é bolsista da Coordenação de Aperfeiçoamento de Pessoal de Nível Superior (Capes).

E-mail: brunasenna@gmail.com

Carmen Teresa Gabriel: É doutora e mestre em Educação pela Pontifícia Universidade Católica do Rio de Janeiro (PUC-RJ), tendo cursado seu pós-doutoramento na Université des Sicences Humaines de Lille 3 (França). É Professora Titular de Currículo da Faculdade de Educação da Universidade Federal do Rio de Janeiro (UFRJ) e professora no Programa de Pós-Graduação em Educação dessa mesma instituição (PPGE/UFRJ). Coordenadora do Laboratório de Núcleo de Estudos de Currículos da UFRJ (LaNEC) e do Grupo de Estudos Currículo, Conhecimento e Ensino de História (Gecceh). Coordenadora do Comitê Permanente do Complexo de Formação de Professores da UFRJ.

E-mail: carmenteresagabriel@ gmail.com

Texto publicado em Currículo sem Fronteiras com autorização dos autores. 